\title{
A Critical Review of Cross-Cultural Conflict Management in Transnational Projects
}

\author{
Thiphaphone KEONOUCHANH \\ School of Overseas Education \\ Yunnan University of Finance and Economics \\ Kunming, China \\ candyytpp@hotmail.com
}

\author{
Cheng Peng* \\ International Business School \\ Yunnan University of Finance and Economics \\ Kunming, China \\ 50665929@qq.com
}

\begin{abstract}
Globalization have stirred up competition and opened up markets for other markets to enter. This wave has also brought about issues of cross-cultural conflicts due to professionals of varying nationalities working together. Analysis of 15 research articles showed that prior knowledge of existing cultural influence and impact on cordial relations on projects must be looked into steps like training on acquiring skills in working in and managing groups in multicultural conditions are done. Conceptual framework, research theme and methodological approaches were discussed.
\end{abstract}

Keywords: cross-cultural conflicts, multiculturalism, conflict, culture

\section{INTRODUCTION}

In the current spate of globalization, it is inevitable to see the move of professionals in varying disciplines into other countries to work on projects. This is evidently observed in construction projects, software development and engineering projects as well. It is currently not out of place to see projects being made up of participants from different countries and expectations of the outcomes are being standardized globally. Nevertheless, domestic projects could also have cross-cultural issues as there are distinctly different ethnic or cultural differences among citizenry; Chinese, Malay, and Indians in Malaysia and the 16 legally recognized cultural and phi logical groups in India [22].

Culture has been considered as a key element in determining the success of transnational projects as different cultures tend to have different It is generally understood that people from different cultures have different opinions about the world thereby holding varying assumptions about life. As businesses are taking advantage of this globalization drive by going international in most part of the last decades, the cultural or national cultural differences cannot be overemphasized. Companies have to consider the cultural concepts in their daily businesses to operate successfully in the global marketplace Kivrak, Ross, Arslan, Tuncan and Egbu, et al [8]. Value, attitude or perception and behavior customs influence environments that have distinct varieties across individuals in teams or workplaces. This degenerate into conflicts due to misreading and misinterpreting the signs and symbols of other cultures.
Inevitably, conflicts might be bound to occur as it is a challenge to prepare for cross-cultural working conditions due to context-based problems and most of the cultural knowledge is not formally referenced, indexed, and filed; rather, it is diffusely distributed within people and society [23]

Extant literature have shown that these conflicts could emerge due to perspectives of personal construct -individual perspective [14]; organizational culture perspectives [10] and national cultural viewpoints [22].Most of these studies delved into one level of analysis at a time ;interpersonal, interorganisational and inter-national however there is a need to look at them as together as they interact with each other (Leidner \& Kayworth, 2006). In further deliberations, researchers delved into issues by which conflicts could emerge [8]; styles of leadership in multicultural teams [11]; training and communication being a form of solution to curtailing the level of conflicts in cross-cultural team .However how the various level of cultural influence conflicts, its resolution have been scarce.Expectedly, few studies have shown the increasing level of expatriate failure due to lack of knowledge in area of cross-cultural skills [2] [3]. Inability to adapt cross-culturally had to do with variations in culture and language, working cordially with colleagues from different cultural backgrounds [5] Apart from costs overruns due to such failures, the dented reputation of the companies of the expatriates could be detrimental to any future engagements with host country' s agencies or businesses. Additionally, the "One Belt and One Road "global developed strategy adopted by the Chinese government geared towards infrastructure development and investments in 152 brings to the fore the issue of cross-cultural relations .This agenda which is to be carried out in continents like Asia, Africa and the others would not be devoid of having to work with professionals from countries with varying cultural exposure. It is therefore opportune to review literature to evaluate the knowledge gap on studies conducted on crosscultural conflicts management specifically with Asia. The insights derived intend to help set an agenda for researchers, practitioners and aid in policy direction in greater extent. The overall aim of this paper is to provide a review of literature concerning cross-cultural conflict management in transnational projects and by so doing examine conceptual approaches,

*Corresponding author 
evaluate methodologies, discuss findings and identify gaps which would set the pace for further research studies.

Subsequently Section II covers framing and methodology for review. Section III and IV entails the presentation and discussion of facts. Research gaps, further research and conclusion is covered in Section V.

\section{FRAMING AND METHODOLOGY FOR REVIEW}

\section{A. Culture and Conflicts}

There hasn't been any consensual definition of culture over the years however varying definitions have sprang up decades past with some focusing on context whilst others give a general view of the concept. Tylor explained culture as a very complex and holistic concept which encompasses all the habits and capabilities that a man acquires being a part of society, which include beliefs, knowledge, morals, art, customs, law and attitudes in 1871. Laroche [6] defines it generally as culture consists in patterned ways of thinking, feeling, and reacting, acquired and transmitted mainly by symbols, constituting the distinctive achievement of human groups. Culture in the context of an organization is viewed as a set of values, beliefs, behaviors, habits and attitudes that helps members understand the organization, for what the organization stands, how it works and what is considered as important" [28]

The same culture which is upheld by a group can be deemed as a monoculture environment. However, in situations where there are differences in values, behaviors and beliefs of the people who come from different cultures which result in Multiculturalism [28]. This condition is prompted by changes in team members or employees having different nationality especially.

In any set up which involve human interactions in achieving a particular objective, be it, a project, organization, committee among others, there is bound to be the occurrence of conflicts

both in monoculture environment or multiculturalism sect.

Conflict is conceived as perceived incompatibility of interests or differences in objectives or disagreement in goals where the disagreement could be with individuals, groups, companies, societies or even nations.

\section{Cross-Cultural conflict Management}

It is undoubtedly a fact that managing a multicultural environment is more challenging than that of monoculture because the former is exposed to more barriers that prevent effective corporation. Barriers could include language, mistrust based on cultural influence hence leading to prejudices and stereotyping. Other barriers include but not limited to communication, inadequate planning of career for employees and their development and ethnocentrism where approval of their own social group with disapproval to another simultaneously [29]. There have been models proposed in terms of managing conflicts in multicultural environment. Thomas and Kilmann proposed competing, compromising, collaborating, accommodating, and avoiding to manage conflicts. These approaches are well represented in literature [30].

\section{B. Classification of Literature}

The overall aim of the study as mentioned earlier is best featured as scoping or mapping study [25][26] As such, it aims at summarizing evidences from studies, examine the scope and nature of research activities, identifying gaps and set the agenda for future research. Webster and Watson [24] recommend that such reviews should be conceptually structured and based on a guiding theory.

Extant literature has shown that discussion on conflicts have bordered on five levels; Personal conflict which is within the person involved (inner pressures) that arise due to other colleagues running against one's beliefs and values [7]. The next level is interpersonal conflict where there is conflict between individuals, then intergroup conflicts, interorganizational conflict and inter-national conflicts. This paper sought to know conflicts in transnational projects hence conflicts therein which could be conceptualized in three levels; Micro, Meso and Micro. Thus, interpersonal conflicts, interorganizational conflicts and inter- national conflicts due to cultural influences shown in Fig 1. The framework was used to discuss the research work reviewed.

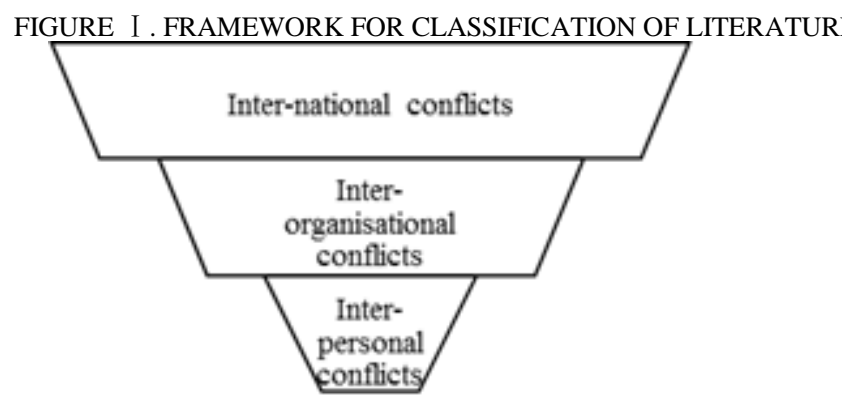

Source: Researcher's construct (Based on Literature Review)

\section{Methodology for Review}

Papers retrieved for the study was centered on both academic source (peer-reviewed, working papers, conference papers) and practitioner sources (non-peer reviewed consultant report, technical reports). Google scholar was therefore the source from which the papers were retrieved as it contains academic and practitioner papers. Fig 2 shows how the shortlisted 15 articles were retrieved for the review. The articles have been shown in Table 1

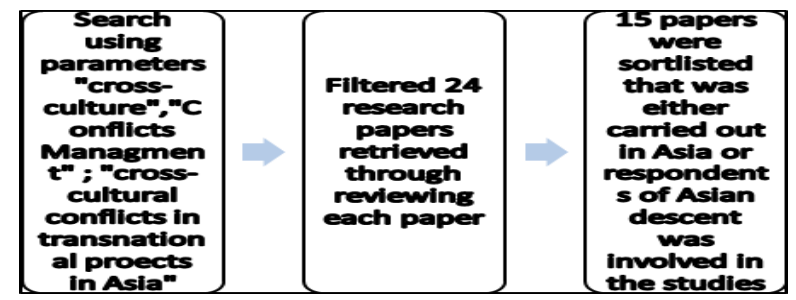

FIG II . SELECTION OF REVIEWED ARTICLES

Source: Researcher's construct 
TABLE I LIST OF REVIEWED ARTICLES

\begin{tabular}{|c|c|c|}
\hline & Citation & TITLE \\
\hline 1 & (Kivrak et al,2010) & $\begin{array}{l}\text { Construction professionals' perspectives on cross- } \\
\text { cultural training for international construction } \\
\text { projects }\end{array}$ \\
\hline 2 & (Montesino,2012) & $\begin{array}{l}\text { Cross-cultural conflict and affirmative action: Inter- } \\
\text { and intra-ethnic dilemmas of Malaysia's } \\
\text { heterogeneous workplace }\end{array}$ \\
\hline 3 & (Ayed et al,2017) & $\begin{array}{l}\text { Agile cultural challenges in Europe and Asia: } \\
\text { insights from practitioners. }\end{array}$ \\
\hline 4 & (Glinkowska,2016) & Managing teams in the multicultural organizations. \\
\hline 5 & (Jehn,1997) & $\begin{array}{l}\text { A qualitative analysis of conflict types and } \\
\text { dimensions in organizational groups. }\end{array}$ \\
\hline 6 & $\begin{array}{l}\text { Xiao and } \\
\text { Boyd,2008) }\end{array}$ & Analyzing cultural problems in international projects. \\
\hline 7 & (Rahim ,1983) & $\begin{array}{l}\text { A measure of styles of handling interpersonal } \\
\text { conflict. }\end{array}$ \\
\hline 8 & (Qamar,2013) & $\begin{array}{l}\text { The relationship between organizational conduct and } \\
\text { national culture. }\end{array}$ \\
\hline 9 & $\begin{array}{l}\text { (Pauliene et } \\
\text { al,2019) }\end{array}$ & $\begin{array}{l}\text { Complex Approach on Multicultural Teams } \\
\text { Management \& Leadership. }\end{array}$ \\
\hline 10 & (Rhein,2013) & $\begin{array}{l}\text { The Workplace Challenge: Cross-Cultural } \\
\text { Leadership in Thailand. }\end{array}$ \\
\hline 11 & (Corey et al,2014) & $\begin{array}{l}\text { Cross-Cultural Differences in Values and Conflict } \\
\text { Management: A Comparison Of Us And Puerto } \\
\text { Rico. }\end{array}$ \\
\hline 12 & $\begin{array}{l}\text { (Di Marco et } \\
\text { al,2010) }\end{array}$ & $\begin{array}{l}\text { Emergence and role of cultural boundary spanners in } \\
\text { global engineering project networks. }\end{array}$ \\
\hline 13 & $\begin{array}{l}\text { (Friedman et } \\
\text { al,2000) }\end{array}$ & $\begin{array}{l}\text { What goes around comes around: The impact of } \\
\text { personal conflict style on work conflict and stress. }\end{array}$ \\
\hline 14 & $\begin{array}{l}\text { (Wall and } \\
\text { Callister,1995) }\end{array}$ & Conflict and its management \\
\hline 15 & (Abugre,2017) & $\begin{array}{l}\text { Cross-cultural communication Imperatives Critical } \\
\text { lessons for Western expatriates in multinational } \\
\text { companies (MNCs) in sub-Saharan Africa }\end{array}$ \\
\hline
\end{tabular}

\section{PRESENTATION OF FINDINGS}

The retrieved articles were further analyzed and findings represented subsequently.

\section{A. Geographical Distribution}

$67 \%$ of the articles retrieved had the country of origin of professionals explicitly stated. There were indications of a mix of culture from other countries and Asian countries like Thailand, Malaysia, japan, India and China. One article centered on another European state and Puerto Rico and researcher considered it. The reason being that nationals of Puerto Rico are of Hispanic culture thus refers to the people, nations, and cultures that have a historical link to Spain thus those colonized by the Spanish Empire in the Americas and Asia, particularly the countries of Latin America and the
Philippines. The remaining percentage had articles that didn't state any country hence was tagged as "unknown" as they were in reviewed literature form $.13 \%$ represented those that indicated a mix of different foreign nationals but did not explicitly indicate the origin hence researcher assumed that there is a probability of Asians being represented in those teams.

\section{B. Methodological Approaches}

A few of the studies reviewed used qualitative Methodology mainly grounded theory and phenology. The instruments used were in-depth interviews, observation (mostly participant observation and questionnaire. The use of quantitative methodology only was rare in the mix but a hybrid of the two methodologies was represented.

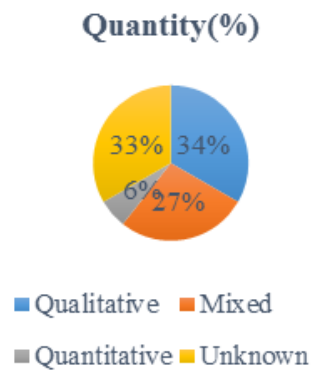

FIG III. RESEARCH METHODOLOGIES

\section{Research Themes}

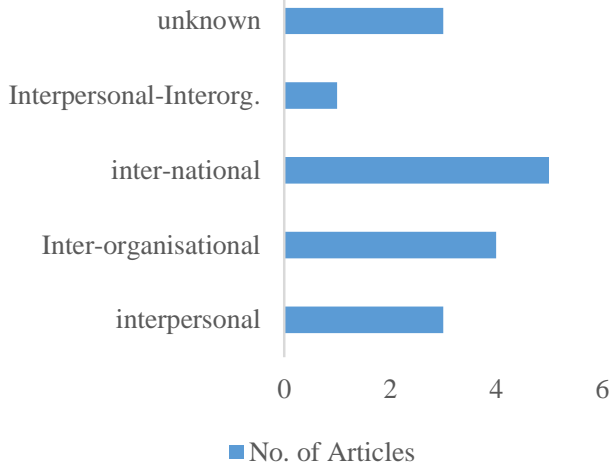

FIG IV. RESEARCH THEMES CUM LEVEL OF ANALYSIS 


\section{Conceptual Framework}

TABLE II. RESEARCH THEMES WITH RESPECTIVE DOMINA

\begin{tabular}{|c|c|}
\hline Research Theme & Conceptual Framework \\
\hline $\begin{array}{c}\text { Interpersonal cultural } \\
\text { influence Conflicts }\end{array}$ & Personal Construct Theory \\
\hline $\begin{array}{c}\text { Inter-organizational cultural } \\
\text { influence conflicts }\end{array}$ & Hofstede's Model \\
\hline $\begin{array}{c}\text { Inter-national cultural } \\
\text { influence of conflicts }\end{array}$ & $\begin{array}{c}\text { Hofstede's Model and } \\
\text { Hall's classification of } \\
\text { Culture, 'dual-concern' } \\
\text { model of conflict } \\
\text { resolution styles. }\end{array}$ \\
\hline
\end{tabular}

IV. DISCUSSION OF FINDINGS

Geographical representation -Asia

The publications that showed professionals from the Asian continents had Japanese as more represented than the other nationals from China, Malaysia and Thailand.

In view of the One Belt and One Road initiative, extensive studies need to be undertaken especially by Chinese researches in order to ensure success in ventures undertaken in different continents earmarked for the initiative.

\section{Research themes}

Interpersonal conflicts: Articles with tag numbers; 2, 7 and 13 took a look at how individuals in cross-cultural teams tend to be exposed by barriers towards cordial relationship with fellow colleagues. Kiviak ET. Al (2010) found that as part of technical expertise, personality traits is needful in choosing team members for a transnational project that involve especially cross-cultural professionals. This was realized to help with adjustment and adaptation. Rahim (1983) on the other hand showed the various forms of handling interpersonal conflicts and went further to develop scales in measuring for the mode of styles. The styles include integration, avoiding, dominating and integrating. Montesino (2011) showed the differences exhibited even among same nationals like Malaysian due to ethnicity differences. Nonetheless, Malays and other Bumiputra majority groups have eventually realized that, they need to share their ancestral motherland with other immigrants.

Inter-organizational conflicts and resolution: Ayed et al (2017) found that cultural background does have an impact on adoption of the agile approach to software engineering. Glinkowska (2016) pointed out that a prerequisite for managing multicultural teams is early managing multicultural teams is early identification of differences between culture that already exists and the desired culture to be worked towards.

Inter-national conflicts and resolution: Pauliene et al (2019) showed that those who have disparities in values can be regarded as culturally linked hence can cause misunderstandings which leads to misinterpretation and misperception. Corey et al (2014) on the other hand discovered that, the cultural influence determines the choice of conflict handling style. For instance, US professionals were significantly more likely to choose accommodating style of conflict resolution as Compared to the Puerto Rico professionals.

\section{Research frameworks}

The dominant model that seemed to spring up in most of the articles reviewed was Hofstede's cultural dimension and that of Hall's cultural dimension. Rhein (2013) and Ayed et al (2017) extensively used Hofstede's cultural dimension of Power distance, uncertainty avoidance, individualism, feminism as theoretical underpinnings for their work. Xiao and Boyd (2008) however used personal constructs theory as its theoretical underpinnings.

\section{Research methodology}

Qualitative research seeks to comprehend situations in their uniqueness as part of a particular context and the interactions there (Denzin \& Lincoln, 1994) whilst Quantitative research determines the extent of a problem or existence of a relationship (Boateng, 2016).Usually as qualitative research seek to explore phenomenon which should be tested using quantitative methodology, the studies that was conducted solely using qualitative research are bound to have a void in the body of knowledge. Validation would be needed to ensure a holistic cover in knowledge as portrayed by Ayed et al(2017).Mixed form of methodology is highly commendable both approaches are carried out in one study bringing some level of finality to nature of the study.

\section{RESEARCH GAP AND FUTURE RESEARCH}

This study identified Contextual, Theoretical and Methodological gaps.

\section{Contextual gaps}

As was earlier mentioned, there should be more studies conducted by Asian researchers for cross-cultural conflicts management within the continent and then extend to that of other continents where Asians are undertaking infrastructure development projects. The success of practitioners of these projects would depend on body of knowledge presented by researchers.

\section{Theoretical gaps}

Although Hofstede's cultural dimension have been used extensively and still in use, there is a need to develop such frameworks that would be more inclined towards cultural dimension on the interpersonal level especially contributing to the Personal Construct theory.

\section{CONCLUSION}

The globalization wave is gaining strength each day hence more markets or investors are seeking to exploit other markets or partake in projects in other countries in order to gain more in this quest, there is the inevitable issue of cross-cultural conflicts as a result of different professionals from varying countries coming together to work on projects. In the wake of the One Belt and One Road initiative, there is a need to review literature that covers cross-cultural conflict management which could inform practitioners and even policy makers in taking decisions. 
This paper analyzed 15 articles that generally centered on professionals with Asian descent and analyzed them on three levels; interpersonal, inter-organizational and inter-national. It was found out that cultural influence cannot be underestimated in terms of conflicts and managing them. Hitherto, technical expertise should not be basis for selection of cross-cultural teams but consideration of personal traits, training on communication and cross-cultural skills adaptation. Contextual and theoretical gaps were identified which set the agenda for future studies to be undertaken by researchers especially on the Asian continent.

\section{REFERENCES}

[1] M.A.Rahim, A measure of styles of handling interpersonal conflict. Academy of Management journal, 26(2),1983, pp.368-376

[2] B.J.Hurn,Pre-departure training for international business managers. Industrial and Commercial Training, 39(1),2007, pp.9-17.

[3] C.H. Liu and H.W.Lee,A proposed model of expatriates in multinational corporations. Cross Cultural Management, 15(2), 2008,pp.176-193

[4] U.Yavas and M.Bodur, Correlates of adjustment: a study of expatriate managers in an emerging country. Management Decision, 37(3), 1999,pp.67-78

[5] A. Jassawalla, C. Truglia and J.Garvey, Cross-cultural conflict and expatriate manager adjustment: An exploratory study. Management Decision, 42(7), 2004,837-849.

[6] L.Laroche, Managing cultural diversity in technical professions. Routledge,2012.

[7] R.L.Kahn,D.M. Wolfe,R.P. Quinn, J.D.Snoek and R.A.Rosenthal.Organizational stress: Studies in role conflict and ambiguity, 1964.

[8] S.Kivrak,A.Ross, G.Arslan,M.Tuncan and C.Egbu, Construction professionals' perspectives on cross-cultural training for international construction projects. In Proceedings of 26th Annual ARCOM Conference", Association of Researchers in Construction Management, Leeds (pp. 6-8),September,2010.

[9] M.U.Montesino,Cross-cultural conflict and affirmative action: Inter-and intra-ethnic dilemmas of Malaysia's heterogeneous workplace. International Journal of Cross Cultural Management, 12(1),2012, pp.115-132.

[10] H.Ayed, B.Vanderose and N.Habra, Agile cultural challenges in Europe and Asia: insights from practitioners. In 2017 IEEE/ACM 39th International Conference on Software Engineering: Software Engineering in Practice Track (ICSE-SEIP) (pp. 153-162), May,2017.

[11] B.Glinkowska, Managing teams in the multicultural organizations. Journal of intercultural management, 8(2),2016, pp.55-70.

[12] K.A.Jehn,. A qualitative analysis of conflict types and dimensions in organizational groups. Administrative science quarterly,1997, pp.530557
[13] H.Xiao and D.Boyd, Analysing cultural problems in international projects. In 24th Annual ARCOM Conference (pp. 1-3),September,2008.

[14] M.A.Rahim, A measure of styles of handling interpersonal conflict. Academy of Management journal, 26(2),1983, pp.368-376

[15] A.Qamar,S. Muneer, A. Jusoh, and H.Idris,The relationship between organizational conduct and national culture. Journal of Economics and Behavioral Studies, 5(2),2013,pp.82.

[16] R.Pauliene, D.Diskiene and E.Matuzeviciute, E., Complex Approach on Multicultural Teams Management \& Leadership. Journal of Educational and Social Research, 2019, 9(2),pp.8.

[17] D.Rhein , The Workplace Challenge: Cross-Cultural Leadership in Thailand. International Studies in Educational Administration (Commonwealth Council for Educational Administration \& Management (CCEAM)),2013, 41(1).

[18] C.M.Corey, L.Y. Fok and D.M. Payne, CROSS-CULTURAL DIFFERENCES IN VALUES AND CONFLICT MANAGEMENT: A COMPARISON OF US AND PUERTO RICO. Journal of Organizational Culture, Communications \& Conflict, 18(2),2014

[19] M.K.Di Marco, J.E. Taylor and P.Alin, Emergence and role of cultural boundary spanners in global engineering project networks. Journal of management in engineering, 26(3),2010, pp.123-132.

[20] R.A.Friedman, S.T. Tidd, S.C. Currall, and J.C.Tsai, ,What goes around comes around: The impact of personal conflict style on work conflict and stress. International Journal of Conflict Management, 11(1),2000, pp.32-55.

[21] J.A.Wall Jr and R.R.Callister, Conflict and its management. Journal of management, 21(3), 1995,pp.515-558.

[22] M.R.Limaye and D.A.Victor, Cross-cultural communication. Crosscultural management, 1995,pp.217-237.

[23] C. Hampden-Turner and A.Trompenaars, Siedem kultur kapitalizmu: USA. Japonia, Niemcy, Francja, Wielka Brytania, Szwecja, Holandia, Oficyna Ekonomiczna, Kraków,2000

[24] S.Webster and R. Watson,Analyzing the past to prepare for the future: writing a literature review. MIS Quarterly ,26 (2) (2002) ,pixie-xxiii.

[25] Kitchenham BA, Budgen D and Brereton OP, Using mapping studies as the basis for further research - A participant-observer case study. Information and Software Technology 53(6),2011,pp. 638-651.

[26] D.Levac,H. Colquhoun and KK. O’Brien , Scoping studies: advancing the methodology. Implementation Science: IS, 5,2010,pp. 69.

[27] M.J.Herskovits, Cultural anthropology,1955

[28] J.E.Griffin . and Jo, C., Complications after superficial plane cervicofacial rhytidectomy: a retrospective analysis of 178 consecutive facelifts and review of the literature. Journal of oral and maxillofacial surgery, 65(11), 2007, pp.2227-2234.

[29] P.Żmigrodzki, Słownik wyrazów bliskoznacznych. Skrypt, 2001

[30] N.W.Chi, Y.Y. Chung and W.C.Tsai, How Do Happy Leaders Enhance Team Success? The Mediating Roles of Transformational Leadership Group Affective Tone, and Team Processes 1. Journal of Applied Social Psychology, 41(6), 2011 pp.1421-1454. 